Revista Multidisciplinar do Nordeste Mineiro, v.2 2019/02

ISSN 2178-6925

\title{
CONTOS DE FADAS NA EDUCAÇÃO INFANTIL: como forma de prazer e magia agregando valores éticos e morais
}

\section{FAIRY TALES IN CHILD EDUCATION: as a form of pleasure and magic adding ethical and moral values}

Eliane Rodrigues Barbosa

Pedagoga, formada pela Faculdade Presidente Antônio Carlos de Teófilo Otoni. E-mail: lianerbarbosa@hotmail.com

Marilda de Souza Lima

Graduada em Pedagogia, em Supervisão Educacional e em Direito. Pós-graduada em Alfabetização e Linguagem, Direito Civil e Direito Processual Civil. Professora e Coordenadora na Faculdade Presidente Antônio Carlos de Teófilo Otoni MG. E-mail: marilda_souza2011@hotmail.com

Geovana Maria dos Santos Gomes

Graduada em Pedagogia. Pós-graduada em Educação Infantil e em Inspeção Escolar e Práticas de Supervisão. Professora na Faculdade Presidente Antônio Carlos de Teófilo Otoni MG. E-mail: geovanamsantos@gmail.com.br

\section{Resumo}

Os contos de fada são veículos infinitos de descobertas e de compreensão de mundo, instigam a criança por meio do mundo mágico da imaginação a vencer barreiras. A leitura deve, desde cedo, ser vital e plena de significação buscando impelir a criança a participar vivamente de seu desenvolvimento global. Deve haver, por parte daquele que escolhe as obras, um olhar crítico voltado para a própria concepção de infância, de modo que despertem emoções como medo, raiva, tristeza, irritação, satisfação e bem estar. A literatura infantil tem a finalidade de promover avanços significativos na mentalidade das crianças e propiciar diversões afirmativas para o seu bem estar, sua felicidade e o sentimento relacionado ao enfrentamento de desafios. Diante disso, os contos de fada são excelentes condutores para a transmissão e construção de valores morais, sem interferência de mediadores. A criança vai se descobrindo e resolvendo seus temores, tristezas, afirmando conceitos de acordo com sua maturidade e raciocínio. Assim, faz-se necessário utilizá-los de maneira mais intensa e direcionada para estimular a sensibilidade das crianças quanto aos valores éticos e morais, além de possibilitar a inserção de tais valores de forma prazerosa, assumindo desafios, respeito às diferenças, rompendo com padrões pré-estabelecidos. Contos de fadas são fundamentais para o crescimento das crianças, possibilitando vencer barreiras impostas pela sociedade, a partir desse entendimento o objetivo desse trabalho é analisar os contos de fadas enquanto instrumento educativo que proporciona o prazer à magia e possibilita a construção de valores éticos e morais nas crianças da educação infantil. A metodologia utilizada foi uma analise literária, utilizando autores como BETTELHEIM (1996); ABRAMOVICHI, (2006), CADEMARTORI (1986) entre outros. 
Palavras-chave: Contos de Fadas. Prazer e Magia. Valores Éticos e Morais. Educação Infantil.

\section{Abstract}

Fairy tales are endless vehicles of discovery and world understanding, instigating the child through the magical world of the imagination to overcome barriers. Reading must, from an early age, be vital and full of meaning, seeking to impel the child to participate strongly in its overall development. There must be, on the part of the one who chooses the works, a critical look towards the very conception of childhood, so that they arouse emotions like fear, anger, sadness, irritation, satisfaction and well-being. The children's literature aims to promote significant advances in the mentality of children and provid ${ }^{1} e$ affirmative diversions for their well-being, their happiness and the feeling related to facing challenges. Faced with this, fairy tales are excellent conductors for the transmission and construction of moral values, without interference by mediators. The child is discovering himself and solving his fears, sorrows, affirming concepts according to his maturity and reasoning. Thus, it is necessary to use them in a more intense and directed way to stimulate children's sensitivity to ethical and moral values, besides enabling the insertion of such values in a pleasurable way, taking on challenges, respect for differences, breaking with patterns preestablished. Fairy tales are fundamental to the growth of children, making it possible to overcome barriers imposed by society, from this understanding the purpose of this work is to analyze fairy tales as an educational tool that provides pleasure to magic and enables the construction of ethical and moral values children. The methodology used was a literary analysis, using authors such as BETTELHEIM (1996); ABRAMOVICHI, (2006), CADEMARTORI (1986) among others.

Keywords: Fairy Tales. Pleasure and Magic. Ethical and Moral Values. Child education.

\section{Introdução}

Os contos de fada são veículos infinitos de descobertas e de compreensão de mundo, instigam a criança por meio do mundo mágico da imaginação a vencer barreiras. A leitura deve, desde cedo, ser vital e plena de significação, buscando impelir a criança a participar vivamente de seu desenvolvimento global. Deve haver, por parte daquele que escolhe as obras, um olhar crítico voltado para a própria concepção de infância, de modo que se despertem emoções como medo, raiva, tristeza, irritação, satisfação e bem estar. A literatura infantil tem a finalidade de promover avanços significativos na mentalidade das crianças e propiciar diversões afirmativas para o seu bem estar, sua felicidade e o sentimento relacionado ao enfrentamento de desafios. Diante disso, os contos de fada são excelentes condutores para a transmissão e morais construção de valores, sem interferência de mediadores. A criança vai 
se descobrindo e resolvendo seus temores, tristezas, de afirmando conceitos conforme sua maturidade e raciocínio.

Compreendendo os diversos benefícios dos contos de fada, torna-se necessário utilizá-los de maneira mais intensa e direcionada para estimular a sensibilidade das crianças quanto aos valores éticos e morais, além de possibilitar a inserção de tais valores de forma prazerosa, assumindo desafios, respeitando às diferenças, rompendo com padrões pré-estabelecidos. Assim como a história "O Lenhador Honesto" exemplifica a edificação de valores éticos e morais, outros contos são fundamentais para o crescimento das crianças, vencendo barreiras impostas pela sociedade.

O objetivo desse trabalho é analisar os contos de fada enquanto instrumento educativo que proporciona o prazer, a magia e possibilita a construção de valores éticos e morais nas crianças da educação infantil.

Em função de uma melhor produção científica e em atenção ao objetivo proposto, fez-se a seguinte pergunta problema: Como os contos de fada ao mesmo tempo em que despertam o prazer e a magia da leitura, podem também contribuir para agregar valores éticos e morais na educação infantil?

Para o desenvolvimento foram situados os tópicos que possibilitam o leitor a um melhor entendimento desse texto. Em primeiro lugar preocupou-se em identificar os contos de fadas e a importância de conta-los, atentando para mostrar que mediante os contos a criança começa a assimilar e abstrair conceitos formadores de caráter, uma vez que estabelece relação entre o "certo e errado", o "bem e o mal". Em um segundo momento, fez-se uma análise sobre os benefícios dos contos de fadas, sempre observando que são diversos, tais como respeito, bondade, justiça, amizade, amor, fraqueza, humildade, diferença, etc. A formação moral da criança ocorre quando ela faz uso da reflexão sobre os contos de fadas, distinguindo as atitudes das personagens e finalmente, optou-se por apresentar os contos de fadas construindo valores, por último fez-se as considerações finais, assinalando a atenção ao objetivo e a problemática apresentada no início do trabalho. A metodologia desta pesquisa, quanto à abordagem, é qualitativa e quanto aos meios foi feito uma revisão literária utilizando livros, artigos, sites e diversas informações mediante trabalhos científicos disponibilizados na internet. 


\section{Os Contos de Fadas e a importância de contá-los}

Os contos surgiram na França por volta de 1697, quando os aldeões se reuniam para aquecer as noites frias de inverno. Relatavam suas vidas, contavam suas histórias sobre fome, miséria, doenças e suas perdas na guerra. Os contos eram carregados de violência e luxúria, nada que pudesse ser dito a uma criança. Para chegar aos ouvidos dos baixinhos, aconteceram algumas mudanças e adaptações. Segundo Bettelheim (1996), é marcante nos contos de fada a criação de impasses existenciais de forma rápida e explícita em que se permite que a criança compreenda e entenda o problema de uma forma mais simples e ela possa confundir a história com o momento em que está vivendo.

Segundo Coelho (2009) os contos de fada, aos olhos da criança, não apenas representam, são mesmo o mundo mágico, rodeado de seres com poderes especiais, onde tudo se resolve com ajuda de uma fada madrinha e é atraente para as crianças porque auxilia diretamente no desenvolvimento psicológico e emocional. Segundo Bettelheim (1996), os contos são distintos de outras literaturas, fornecem para a criança a sua identidade, é uma modalidade de leitura diferente, desenvolve o interesse da criança, sugerindo descobertas significativas para a construção mais afirmativa do seu caráter.

Os desafios apresentados nas histórias são diversos, entre eles 0 enfrentamento de situações que envolvem perigo, sendo assim, a criança adquire maturidade com o martírio vivido pelo personagem da história.

Em diversos contos de fada, a atuação é vagarosa, entretanto preserva um princípio fundamental de alto nível, percebendo, inclusive, que há um destaque no talento moral do personagem principal. Os mocinhos são corajosos, perseverantes, gentis e bonitos. Os malvados são desprimorosos e fisicamente descaracterizados. Para Bettelheim (1996), em função do seu comportamento desproporcional com os valores éticos e morais o castigo acontece, porém de maneira mais natural, não promovendo um choque psicológico, mas conduzindo a criança a perceber que atitudes inadequadas serão punidas.

Por outro lado, a história contrapõe as atitudes do vilão, apresentando o mocinho, que em função de seus modos coniventes com o bom 
comportamento social, sempre se casa com a mocinha e o conto termina com o tradicional: "felizes para sempre". A alegoria da qual surgem certas situações narradas na história, impõe ao ouvinte a condição de se envolver de tal forma, que se inclui na narrativa contada.

Qualquer criança, por mais estimada e adorada que seja, está perante 0 comando de adultos, e em sua imaginação contém a ideia de que este comando não é correto, sempre achando que um dia vão estar livres em um lugar melhor do que vivem no momento, e quando se libertarem dos adultos serão vencedoras, assim as narrativas conduzem o amor próprio da criança, mostrando que futuramente vão encontrar a felicidade.

Notoriamente os contos de fadas não são as únicas narrativas que podem ser lidas, como aponta Cademartori (1986), existem muitas outras, entretanto, é a narrativa mais acessível de significados, em virtude de seus fundamentos e questões levantadas. O vocabulário simbólico desses relatos facilita a criança a se colocar em vários personagens e ocasiões, sendo que cada narrativa tem um ensinamento intrínseco, e ela mesma descobre e aprende as mensagens passadas pelos contos sem ser forçada, mas de maneira divertida e descontraída os quais auxiliam em vários pontos para o desenvolvimento da criança e adolescente. Esses pontos podem mudar de um conto para outro; contudo, de maneira geral, estes possibilitam a evolução da prudência, da sagacidade, do questionamento, da criação, da fantasia, da realidade e da transmissão de valores morais.

Contar história para o mundo infantil é um ponto importante para o seu desenvolvimento e contribui para alguns aspectos essenciais, como a curiosidade e o enfrentamento de desafios. Quando se conta uma história, a criança fica curiosa querendo saber todos os detalhes, como termina e o motivo pelo qual isso ou aquilo aconteceu, sendo que também neste momento a criança desenvolve o senso crítico.

Segundo Dohme (2003) ao ouvir um conto e refletir sobre ele, a criança começa a ter noção das situações e ter opiniões sobre cada assunto contado, despertando a criatividade. Neste sentido, a criança ao ouvir a história, contar e recontá-la, a sua imaginação possibilita a criação de outras histórias, criativas e que comumente apontam a resolução de conflitos. 
Ouvindo narrativas, ela terá o senso do que é certo e do que é errado. Os contos infantis sempre terminam apontando para a moral da história, o que favorece de forma significativa, o desenvolvimento da criança e ela passa a entender, por meio das histórias contadas, o que é uma atitude correta e o que é uma atitude ruim, pois tais dão essa noção para a criança.

Quando se conta uma história para crianças os personagens criam vida na cabecinha delas, que imaginam os animais, os vestidos, sapatinhos, cada detalhe. Isso desperta e aguça a imaginação dela, segundo Fanny Abramovich (2006):

É também suscitar o imaginário, é ter a curiosidade respondida em relação a tantas perguntas, é encontrar outras ideias para solucionar questões como as personagens fizeram. É uma possibilidade de descobrir o mundo imenso dos conflitos, dos impasses, das soluções que todos vivemos e atravessamos. (Fanny Abramovich 2006, p.17)

Abramovich aponta em seus estudos que os contos de fada são instrumentos positivos para estimular a criança na resolução de conflitos internos em que vive neste período da infância. É fundamental destacar que as crianças se apropriam das histórias de formas diversas e muitas vezes se identificam de tal maneira com o personagem que subjetivamente criam soluções para lidar com alguns problemas que estão vivenciando internamente após observar desafios enfrentados por personagens de determinados contos.

Em se tratando dos contos de fada, pode-se compreendê-los como uma ferramenta indissociável a uma boa prática pedagógica na educação infantil e é importante ressaltar que como aponta Vigotsky (1992), a criança deve escutar várias histórias no começo da aprendizagem, para que além da aprendizagem, passa a ser um leitor e trilhar uma estrada repleta de conquistas e percepção de mundo, além de que essas histórias vão contribuindo para a formação do seu caráter.

Daí é imperativo a contação de histórias na infância, o que é algo mágico e prazeroso e estas permanecem no seu imaginário no decorrer de sua existência e vivenciam experiências inimagináveis que só um livro pode proporcionar. Segundo Abramovichi (2006), é escutando histórias que se expõem os sentimentos marcantes, como sofrimentos e alegrias. É um contentamento ouvi-las, uma sensação encantadora que introduz a criança em um mundo novo, cheio de descobertas fantásticas. 
Sendo assim, fica clara a importância desse mundo mágico desde os primeiros meses de vida do bebê, visto que aumenta a capacidade intelectual sendo inúmeros os benefícios dos contos de fadas já na primeira infância, uma vez que apresentam situações que lidam com o emocional da criança.

\title{
2.1 Benefícios dos contos de fadas
}

Os benefícios dos contos são inúmeros, uma vez que apresentam situações que lidam com obediência, compaixão, razão, simpatia, amor, fragilidade, simplicidade, diferenças raciais e econômicas. Para Bettelheim (1996), os contos de fada admitem a criança instruir-se mais sobre as dificuldades familiares, das pessoas humanas e sobre as soluções adequadas para seus problemas em uma sociedade. Mais do que qualquer outro tipo de narrativa acessível por uma criança, segundo ele:

\begin{abstract}
Aplicando o modelo psicanalítico da personalidade humana, os contos transmitem importantes mensagens à mente consciente, a pré-consciente e à inconsciente, seja em que nível for que cada uma esteja funcionando no momento. Lidando com os problemas humanos universais, particularmente os que preocupam 0 pensamento da criança, essas histórias falam ao seu ego que desabrocha e encorajam o seu desenvolvimento, ao mesmo tempo em que aliviam pressões pré-conscientes e inconscientes. À medida que as histórias se desenrolam, dão crédito consciente às pressões do id, mostrando caminhos para satisfazê-las que estão de acordo com as exigências do ego e do superego (BETTELHEIM, 1996, p.14).
\end{abstract}

Para diversas pessoas, os livros que eram lidos quando crianças são de grande valor "precioso", "virtuoso" e têm um lugar especial na estante. Segundo Tatar (2004), mesmo sem entender, utilizamos as narrativas para percorrer a vida e resistir a um mundo reprimido por uma sociedade cruel. Em razão a isso criou um mundo de imaginação que permite alforriar da realidade indigesta da vida habitual e se entregar às distrações "libertadoras" de vencer gigantescos mal feitores, bruxas más, cucas e dragões.

Segundo a autora, os contos de fada narram às crianças o que elas impensadamente compreendem, que o caráter humano não é exclusivamente bom, existem os bruxos e os mocinhos, que o confronto é verdadeiro, que a vida é ríspida antes de encontrar a felicidade; assimilar o conto dessa maneira acalma seu coração com relação seus medos particulares e a seu juízo de 
personalidade e egocentrismo. Leitura é fundamental, por meio dela, analisa-se valores individuais e informações dos outros.

Do mesmo modo que as pessoas, os livros são capazes de surpreender, formar e informar leitores, conduzir para lugares distantes, planetas inimagináveis e criar sujeitos aprendizes e instrutores. Ouvir histórias é o começo do conhecimento para um indivíduo ser um bom leitor, apresentando uma jornada inteiramente infinita de descobertas e de percepção de mundo. Os contos alcançam a imaginação e conduzem a criança a aguçar a sua curiosidade, que imediatamente é replicada no decorrer da leitura dos contos. É uma probabilidade de se deparar com um planeta extraordinário das confusões, dos embaraços, das saídas que todos convivem e cruzam de um modo ou de diverso, pelo meio dos enigmas que vão sendo afrontados ou não, definidos ou não, pelas personalidades de cada conto, (Pires, 2000). Desse modo, a leitura dos contos na Educação Infantil motivam o desenvolvimento e a formação do caráter das crianças e, por meio deles, desenvolvem a capacidade de lidar com os embates da vida e as circunstâncias que os cercam.

$\mathrm{Na}$ Educação Infantil, o surgimento da leitura tem a necessidade de vir seguida de entusiasmo do professor, o qual deve agir como intermediário, para que a leitura cresça com toda eficácia entre as crianças e para que se construam bons leitores é preciso amor pela leitura. (Kleiman, 2007). O primeiro contato com a leitura deve ser uma fonte de entretenimento, prazer e valorização da própria leitura. Algumas crianças têm a sorte de conviver em domicílio que esta se faz atual desde o princípio, outras só têm o acaso de encontrá-la ao entrar no jardim de infância. É de extrema importância que pais e educadores reconheçam e estimulem a ação de ler.

É importante ressalvar que as crianças que têm em casa pais leitores, começam a ler na tenra idade e mesmo não sabendo ler, estão sempre rodeados de livros e se familiarizam com a leitura desde cedo.

Segundo Lajolo (2002), quanto mais intensa a compreensão de mundo e de vida, mais profundamente se decifra, num ciclo quase infinito que inicia na escola, mas que não pode encerrar-se nela. O estímulo ou excitação é a peça fundamental para se formar exímios leitores. Segundo os PCNs (1997), para tornar os educandos bons leitores - para ampliar, muito mais do que a 
competência de ler, o desejo e a obrigação com a leitura - a escola terá de motivá-los profundamente, pois aprender a ler (e também ler para aprender) solicita empenho.

O mérito da leitura precisa ser atingido assim como do educador na experiência de fazer uma divulgação da leitura de maneira atraente, abrindo os olhos das crianças, despertando curiosidades, afinidade e admiração pelo livro. Conforme o Referencial Curricular Nacional para a Educação Infantil, (1998), a realização da leitura é cultural. Assim como o educador faz uma opção precedente da narrativa que irá contar para as crianças, independente da idade delas, tendo cautela para a clareza e requinte com o conteúdo lido, ele deixa as crianças edificarem vários sentimentos pelos livros. A obra irreal desenvolve e movimenta as fronteiras da imaginação. Quando alguma pessoa lê ou conta histórias, reporta-se ao tempo em que ocorreu o episódio contado e tornando integrantes da história. Segundo Kaufman \& Rodríguez (2005), o conto quando narrado ou escutado tem o força de abrir os olhos do leitor de uma maneira que aflora emoções extraordinárias, o qual inicia mostrando uma situação de sensatez oferecendo situações e fatos que se transformam em solução de um jeito fácil, sem complicação.

O conto pode ser uma condição da imaginação espontânea ou alguma narrativa que surgiu habilmente mediante um fio de vida real e é essa afinidade que faz despertar algo de grande importância por meio do mundo fantástico cuja magia é essencial para o crescimento da criança. Há conceitos muito mais intensos nos contos de fada que se pode imaginar e muito mais aprendizado do que a vida adulta possa ensinar, pois estes delineiam fatos magníficos em histórias ingênuas e meigas, porquanto contar histórias é o método de agarrar os segredos da existência em versos.

Assim como na história de "Chapeuzinho Vermelho" narrada pelos Irmãos Grimm (2014) que ensina às crianças a não confiar em estranhos e não desobedecer aos pais. Esse conto traz um ensinamento importante aos pequeninos, mesmo que tais contos não devem ser atrelados à uma Pedagogia que oferece respostas, estão atrelados à Pedagogia que mediante os contos desperta o interesse da criança em ler e por si só compreender o significado, a própria criança vai associando o que pode e o que não pode. 
Contudo, segundo Corsos (2006) o conto de "Chapeuzinho Vermelho" narra a perda da inocência e a descoberta da sedução, curiosidade do sexo oposto, ao confiar em um estranho por pura ingenuidade, isso retrata 0 amadurecimento da criança. Os contos mais do que qualquer outro tipo de história infantil narram suas preocupações internas e de um modo inconsciente elas compreendem, sem ignorar as batalhas interiores possibilitando assim o desenvolvimento da criança.

A menina da capa vermelha deu ouvidos ao desconhecido e acabou se complicando. $\mathrm{Na}$ narrativa isso mostra que as aparências enganam, conduzindo a criança para uma imersão de experiências na educação moral e assim como nos contos de fada, na vida também existe uma punição, que intimida a criança, e a faz pensar e analisar que o crime e a desobediência não compensam e as pessoas malvadas sempre perde no final e quando empregados no momento certo, são benéficos e transmitem valores práticos e fáceis de serem compreendidos pelas crianças. Piaget (1975) relata na sua teoria do desenvolvimento, que a criança se mostra reclusa em suas interações sociais e que até desenvolver a teoria da mente, elas são egocêntricas e, às vezes, não têm noção das consequências de seus atos, sendo assim, os contos de fadas muitas vezes tem meios necessários de promover e fortificar valores importantes para uma criança em seu confronto com as tempestades da vida.

Sendo de grande importância a construção moral da criança quando ela analisa o que está lendo ou ouvindo, singularizando suas atitudes e as dos personagens e construindo valores, consolidando sua formação moral, o qual elucida e favorece o desenvolvimento da personalidade da criança oferecendo significados que enriquecem a existência da criança.

\section{Construindo Valores}

Para pesquisar os conceitos morais e éticos dos contos de fadas é de suma importância uma rápida analise sobre os conceitos de valores. Segundo Bueno (2007), ética é os deveres do homem para com Deus e a sociedade, moral trata-se dos costumes e deveres do homem, relativos aos bons costumes. Como se explica no dicionário, ética seria então atitudes do indivíduo, a moral diz respeito às regras de se proceder em uma sociedade. Valores morais e éticos inseridos na educação por meio dos contos de fadas têm grande contribuição na formação da criança. 
Mediante uma leitura prazerosa e descontraída os pequeninos abordam assuntos polêmicos que auxiliam em sua formação social, assim fortalecendo seus valores e construindo uma formação ética e moral concreta, segundo ele.

Os contos de fadas são tão significativos para as crianças, ajudandoas lidar com problemas psicológicos do crescimento e da integração de suas personalidades - algumas limitações, sérias, mas necessárias, tem que ser aceitas. (BETTELHEIM, 1996, p.23).

A criança ao se deparar com conflitos apresentados pelos personagens da historia, como a mentira, desobediência, a exclusão pela aparência entra em contato com questionamentos sobre conceitos que o destina ao comportamento e atitudes aos valores éticos e morais de uma sociedade.

De acordo com Chauí (1999) a ética aplica limites e garante o controle de atitudes que prejudica uma classe social. Os contos de fadas carregados de valores éticos e morais, por apresentarem condutas humanas e facilitar uma observação sobre exemplos de comportamentos globais.

Bettelheim (1980, apud Melo e Filho, 2006) aponta que o conto de fadas salienta de maneira explicita a diferença entre o justo e equivocado. Assim como nas narrativas de branca de neve e sua madrasta Cinderela e sua madrasta, João e Maria e a bruxa antropófaga são modelos que ajudam a criança a adquirir uma compreensão moral e conhecer a diferença entre o bem e o mal, possibilitando situações em que ela própria tenha atitude ética de como enfrentar o problema de maneira prudente.

Devries e Zan, (1998), enfatizam que ao iniciar disciplinas de ética e moral na educação infantil, o propósito tem que estar centralizado no bom senso estimulando a criança a refletir sobre o outro no decorrer da procura da resposta, reconhecendo a igualdade e tendo consideração com seu semelhante. Sendo assim mediante os contos e fadas a criança aproximar-se de duvidas referentes à ética e a moral expondo temas complicados de maneira simples, tranqüila e engraçada.

Saraiva (2001), aponta que o fato dos contos de fadas apresentarem uma organização de fácil entendimento, provavelmente por essa razão é enorme a 
aceitação deles pelas crianças. Portanto por serem aceitos pelos pequeninos proporcionam um conhecimento de grande valor que proporciona 0 envolvimento com questões éticas e morais que são cruciais na convivência em sociedade.

Esses valores necessitam ser trabalhados a partir da infância, pois nesta etapa vão assumindo a identidade, valores e a formação do caráter. Bennett, (1995), no livro das virtudes revela a importância dos valores como amabilidade e a compaixão, valores que as crianças precisam ter como exemplos para sua formação moral, caráter não pode ser imposto de maneira agressiva tem que ser moldados com exemplos de atitudes corretas.

Percebe-se que os contos de fadas contribuem pra essa construção de caráter dando exemplos certos, sem a intervenção de mediadores, atuando de forma espontânea, ampliando o conhecimento da percepção colaborando na formação do senso critico da criança criando uma aprendizagem significativa.

\section{Considerações finais}

Esse trabalho foi construído no sentido de compreender os contos de fadas enquanto instrumento educativo que além de proporcionar a magia vai construindo na criança uma apreciação pelos valores éticos e morais.

No percurso da revisão literária ficou evidente que é significativo como recurso educativo o uso dos contos de fadas, pois ao mesmo tempo em que desperta o prazer e a magia pela leitura, os contos auxiliam para agregar conceitos na formação e construção dos valores morais e éticos, proporcionando um desenvolvimento educacional significativo, como pode-se perceber além do encantamento pela magia, proporciona o envolvimento com assuntos sociais de caráter cultural que permitem à criança uma aprendizagem importante e divertida e ademais, sem constrangimentos.

No decorrer de cada narrativa ela saberá diferenciar o "bem e o mal" , "certo e errado" aprendendo que ser honesto e virtuoso tem sua recompensa e por esta razão o crime não compensa, preservando assim a verdade e respeito construindo valores e auxiliando na formação de um sujeito critico e reflexivo de maneira lúdica e objetiva.

Portanto os contos de fadas na educação infantil desperta e promove uma construção de valores que agrega grandes benefícios para a formação de toda uma vida, contribuindo para o desenvolvimento de seu caráter e equilíbrio emocional, moldando uma maturidade psicológica. 


\section{Referências}

ABRAMOVICHI, Fanny Literatura infantil: Gostosura e bobices. São Paulo: Scipione, 2006.

BETTELHEIM, Bruno. A psicanalise dos Contos de Fada. Rio de Janeiro: Paz e Terra, 1996.

BENNETT, J. William. O Livro das Virtudes. Volume 1 São Paulo: Nova Fronteira , 1995.

BUENO, Silveira. Minidicionário da língua Portuguesa. $2^{\circ}$ ed. São Paulo, FTD, 2007.

BRASIL. Parâmetros Curriculares Nacionais: Língua Portuguesa ( $1^{\underline{a}}$ a $4^{\text {a }}$ série), Brasília, 1997.

CADEMARTORI, Lígia. O que é literatura infantil. Editora Brasiliense São Paulo 1986.

COELHO, Nelly Novais. Contos de Fadas: símbolos mitos arquétipos. São Paulo: Paulinas, 2009.

CORSO, Liechtenstein, Diana CORSO, Mario. Fadas no Divã: Psicanalise nas Historias Infantis, Porto Alegre: Artmed, 2006.

CHAUI, Marilena. Convite a Filosofia. São Paulo: Ática, 1999.

DEVRIES, Reta \& ZAN Betty. A ética na Educação Infantil: o ambiente sócio moral na escola. Porto Alegre: Artes médicas, 1988.

DOHME, Vania D'Angelo. Técnicas de Contar Histórias: pais: um guia dos pais contar historia para deus filhos. São Paulo: Informal, 2003.

GRIMM, Jacob, GRIMM, Willhelm. Once Upon a Time: uma antologia de Contos de Fadas. $1^{\circ}$ Ed. São Paulo: Planeta, 2014.

KAUFMAN, Ana Maria \& RODRÍGUEZ, Maria Elena. Escola, leitura e Produção de textos. Porto /alegre: Artes Médicas, 2005. 
KLEIMAN, Ângela. Oficina de Leitura: teoria e prática. 11ª Edição, Campinas, SP: Pontes, 2007.

LAJOLO, Marisa. Do Mundo da Leitura para a Leitura do Mundo. $6^{\underline{a}}$ ed. São Paulo: Ática, 2002.

MELO Daisy Mendes; FILHO, Evandro Abreu Figueiredo. Os Contos na Formação Ética e Moral de Crianças da Educação Infantil. Psicologado. Edição 03/2016. Disponível em < https://psicologado.com.br/atuacao/psicologia-escolar/os-contos-na-formacaoetica-e-moral-de-criancas-da-educacao-infantil

PIAGET, J. A formação do símbolo na criança: imitação, jogo, sonho, e representação. Rio de Janeiro: Zahar, 1975.

PIRES, Dilea Helena de Oliveira. "livro... Eterno livro...” In: Releitura. Belo Horizonte: Março de 2000, vol.14.

SARAIVA Juracy Assmann. Literatura e Alfabetização: do plano do choro ao plano da ação. Porto Alegre: Artmed, 2001.

TATAR, Maria. Contos de fadas: Edição comentada e ilustrada. Rio de Janeiro: Jorge Zahar Editores, 2004.

VIGOTSKY,Lev Semenovitch. O desenvolvimento psicológico na infância. São Paulo: Martins Fontes, 1992. 